\title{
Evaluation of Mean Platelet Volume in Diabetes Mellitus and Its Role in Microvascular Complications
}

\author{
Sruthi Prasad ${ }^{1 *}$ and Vibha Prakash² \\ ${ }^{1}$ Department of Pathology, Kempegowda Institute of Medical Sciences, Banashankari 2nd stage, Bangalore 560070, Karnataka, India \\ ${ }^{2}$ Undergraduate, Kempegowda Institute of Medical Sciences, Banashankari 2nd stage, Bangalore 560070, India
}

\begin{abstract}
Background: Diabetes mellitus(DM) is a metabolic disorder characterised by hyperglycaemia. The hyperglycemia results in altered platelet function as reflected in the platelet indices (mean platelet volume-MPV, platelet distribution width and plateletcrit). Altered platelet function has also been implicated in the occurrence of diabetic vascular complications. Evaluation of platelet indices may serve to provide an insight into the pathogenesis of DM as well as possibly evaluate the risk of progression of the disease. The aim of the current study was to evaluate the MPV in patients with DM and compare it with a non-diabetic control group. We also attempted to determine the association between MPV and microvascular complications within the diabetic cohort.
\end{abstract}

Methods: The study was carried out on patients with diabetes mellitus, attending the medicine out-patient department. Relevant history was taken and fasting blood glucose and hematological parameters (platelet indices and complete blood counts) were assessed as a part of the routine investigations requested by the physician itself. A total of 320 diabetics were screened for the study. After applying exclusion criteria, 52 diabetics were included in the study. We also included 62 non-diabetic, age and sex matched controls in the study. Statistical analysis was performed.

Results and Conclusion: MPV levels were significantly higher in diabetic patients when compared to non-diabetic controls. Also, within the diabetic group, MPV values were significantly higher in diabetics with microvascular complications (24 patients) as opposed to the ones without.

MPV is a simple, convenient and cost-effective routine hematological investigation which plays a significant role in the pathogenesis of diabetes mellitus and may serve as an useful prognostic marker to herald the onset of microvascular complications in the diabetic population.

Keywords: Diabetes Mellitus, Mean Platelet Volume, Microvascular Complications, Platelets, Fasting Blood Glucose.

\section{Introduction}

Diabetes mellitus (DM) is a metabolic disorder which has attained the proportions of a global pandemic. ${ }^{[1]} \mathrm{It}$ has proved to be a cause of great concern, especially in a developing country like India due to its high degree of morbidity and ubiquitous prevalence. It is estimated that by 2030, there would be 79.4 million individuals afflicted with diabetes in India. ${ }^{[2]}$ The fact that this condition requires close monitoring and continuous follow-up adds to its status as being one of the leading worldwide health issues. DM is characterized by chronic levels of hyperglycemia resulting in complications affecting almost all the organs in the body. ${ }^{[1]}$ These complications further enhance the morbidity and mortality associated with DM.

Extensive research is being done on establishing a relationship between diabetes mellitus and platelet indices (mean platelet volume- MPV, plateletcrit- PCT, and platelet distribution width- PDW). Altered platelet morphology and function have been reported in patients with diabetes mellitus (DM) and MPV was found to be significantly higher in them, ${ }^{[3,4]}$ thereby playing a crucial role in the development of microvascular complications (diabetic nephropathy, neuropathy, and retinopathy) and macrovascular complications (coronary artery disease, transient ischemic attacks, peripheral arterial disease, and stroke). ${ }^{[4]} \mathrm{A}$ few studies have also noted that the mean MPV is higher in diabetics with poor glycemic control and in those with vascular complications as opposed to those without the same. ${ }^{[5]}$

Mean platelet volume (MPV) reflects the average size of platelets present in a person's blood sample. ${ }^{[6]}$ It is a marker indicating subclinical platelet activation and its elevated level is an independent risk factor for various vascular episodes. ${ }^{[7]}$ Automated cell counters have made platelet indices like MPV routinely available in most clinical laboratories. Hence, there is scope to make better use of the platelet parameters generated ${ }^{[6]}$ by employing MPV as an important, simple, effortless, and cost-effective tool to understand the pathogenesis of the disease. It can probably also serve as an independent predictor of impending acute events and to necessitate prophylactic therapy in the form of anti-platelet agents. ${ }^{[8]}$ 
The objectives of the current study are; 1. To evaluate the MPV in patients with DM and compare it with a non-diabetic control group. 2. To determine the association between MPV and microvascular complications within the diabetic cohort.

\section{Material \& Methods}

The current study was carried out on patients with diabetes mellitus, attending the medicine OPD at a tertiary care hospital. It also included age and sex matched controls. Ethical approval was obtained from the Institutional Ethics Committee before the commencement of the study. Informed consent was procured from the participants at the time of recruitment into the study.

History was elicited from them to acquire information about the status of hypertension and intake of any antiplatelet medication. The presence of vascular complications was identified based on the history obtained/ clinical examination performed (for neuropathy) and the investigations carried out (fundoscopic examination for retinopathy, albuminuria for nephropathy). Data thus obtained was recorded methodically. Hematological parameters (platelet indices and complete blood counts$\mathrm{CBC}$ ) and fasting blood glucose (FBG) were assessed as part of the routine investigations requested by the physician itself.

A total of 320 diabetics were screened for the study. From this group, patients with anaemia (hemoglobin $<12 \mathrm{~g} / \mathrm{dl}$ in males $\& 11 \mathrm{~g} / \mathrm{dl}$ in females), hypertension, infection (as reflected by leukocytosis), thrombocytopenia, thrombocytosis, malignancy and pregnancy were excluded. Patients with history of intake of any anti-platelet medication (aspirin and clopidogrel) were also excluded from the study. After exclusion, 52 patients were included in the study group. We also included 62 non diabetic controls (after application of the exclusion criteria) for the study.

Venous blood samples were collected in EDTA and biochemistry tubes, and tested within 1 hour of collection to minimize variations due to sample aging. Samples were maintained at room temperature. The anticoagulated blood was analyzed in automated hematological analyzers (SYSMEX XT1800i) to obtain the platelet indices and CBC. FBG was measured by hexokinase enzymatic method (Roche Cobas C 501 chemistry analyser).

The MPV values in the diabetic group were compared with that of the control group. The diabetics were divided into two groups based on the presence or absence of microvascular complications and the MPV values were further compared between them.

The data thus obtained was compiled and statistically evaluated. Statistical analysis was performed using SPSS statistics program version 16. A $P$ value of less than 0.05 was considered statistically significant.

\section{Results}

The current study included 52 diabetic patients ( 21 females and 31 males).

The non-diabetic control group of 62 patients included 26 females and 36 male patients. The age of the patients within the diabetic group ranged from 32 yrs to 76 yrs with a mean age of 52.21 yrs. Within the control group, the age of the patients ranged from 19 yrs to 78 yrs with a mean age of $41.02 \mathrm{yrs}$.

The mean FBG and MPV in the diabetic group were $219.04 \mathrm{mg} / \mathrm{dl}$ and $10.31 \pm 0.82 \mathrm{fl}$ and that in the nondiabetic control group were $102.42 \mathrm{mg} / \mathrm{dl}$ and $9.76 \pm 0.71$ $\mathrm{fl}$ respectively. The mean MPV was significantly higher in the diabetic group as opposed to the non-diabetic group (P value $=0.000289$ ) (Table 1$)$.

Of the 52 diabetic cases, 24 had microvascular complications. The mean MPV of patients with microvascular complications was $10.68 \pm 0.77 \mathrm{fl}$ and those without complications was $9.99 \pm 0.73 \mathrm{fl}$. MPV was significantly elevated in the diabetic group with microvascular complications (P value $=0.002321)($ Table 1$)$.

Table 1: Mean values of Age, MPV (mean platelet volume) and fasting blood glucose (FBG) according to subgroups: nondiabetics, diabetics without vascular complications and diabetics with vascular complications.

\begin{tabular}{|l|l|l|l|l|}
\hline & $\begin{array}{l}\text { Non - Diabetic } \\
\text { Control Group }\end{array}$ & Diabetics & $\begin{array}{l}\text { Diabetics without } \\
\text { vascular complications }\end{array}$ & $\begin{array}{l}\text { Diabetics with vascular } \\
\text { complications }\end{array}$ \\
\hline Mean Age $(\mathrm{yrs})$ & 41.02 & 52.21 & 52.79 & 51.54 \\
\hline Mean MPV (fL) & 9.76 & 10.31 & 9.99 & 10.68 \\
\hline Mean FBG $(\mathrm{mg} / \mathrm{dL})$ & 102.42 & 219.04 & 216.07 & 222.5 \\
\hline
\end{tabular}




\section{Discussion}

Diabetes mellitus, is characterized by varying levels of hyperglycemia. ${ }^{[9]}$ Several lines of evidence indicate that hyperglycemia induces the production of larger platelets. ${ }^{[10]}$ This can be quantified as MPV by clinical hematology analyzers, which generally varies between 7.5 to 10.5 fl. ${ }^{[11]}$ MPV may be affected by various factors such as anemia, leukocytosis, thrombocytosis, thrombocytopenia, infections, hypertension, dyslipidemia, pregnancy, malignancy, and intake of antiplatelet medication. ${ }^{[10]}$

It has been demonstrated that alterations in platelet and endothelial function that favor thrombosis occur early in the diabetic state and may contribute to microvascular disease. Based on this postulate, there are several ongoing studies on antiplatelet agents, that maybe employed in the preventive treatment of diabetic vascular disease. ${ }^{[12]}$

The current study shows that the MPV values were significantly increased in diabetic patients when compared to non-diabetic controls (mean MPV in diabetics $10.4 \pm 0.73 \mathrm{fl}$, mean MPV in non-diabetics $-9.74 \pm 0.72 \mathrm{fl}$, $P$ value $=0.0002$ ) which coincides with the results of other researchers. $[1,3,4,8,13,14,15,16,17,18]$

Higher MPV in DM could be explained based on few of the following hypotheses. Firstly, plasma glucose is a major source of energy for platelets. ${ }^{[1]}$ Under basal conditions, $40 \%$ to $50 \%$ absorbed glucose is used for glycogen production. ${ }^{[1]}$ Due to chronic hyperglycaemia, platelets are overwhelmed with glucose and are subjected to synthesis of glycogen and glycosylation of certain proteins. The increased glycogen content in turn contributes to small percent of increase in the MPV. ${ }^{[19]}$ Therefore, MPV reflects the hyperglycemic status of a diabetic individual. Another theory, to support increased MPV in hyperglycaemic patients, is osmotic swelling of platelets due to raised levels of some glucose metabolites. ${ }^{[2]}$ The third theory, states that there is higher platelet turnover in DM, resulting in younger platelets which are both larger and more metabolically active. ${ }^{[20]}$

The increased reactivity and activation of platelets in diabetic patients may also be attributed to several biochemical factors such as hyperglycaemia, hyperlipidemia, insulin resistance, prolonged inflammatory and oxidant state and also, increased expression of glycoprotein receptors and growth factors. ${ }^{[1]}$ Hyperglycaemia leads to increased platelet activity by increasing non-enzymatic glycation of proteins on the platelet surface, enhancing osmotic effects of glucose and activation of protein kinase C. ${ }^{[21-23]}$ Insulin

www.pacificejournals.com/apalm also acts directly by controlling the platelet function via a functional Insulin Receptor and attenuates the platelet aggregation effect of agonists in healthy non-obese individuals. ${ }^{[21-23]}$ Overall, a prolonged hyperglycaemic state leads to various microvascular and macrovascular complications and the platelets add up these effects. ${ }^{[20,23]}$

Research is also being carried out in the diabetic population to find a correlation between increased MPV and the presence of microvascular complications with many studies suggesting a strong association between the two. ${ }^{[12}$, ${ }^{24}$ The current study is in corroboration with the same and is in agreement with the results of other researchers, ${ }^{[3,18,25,26]}$ wherein there is a significantly higher MPV among the diabetic patients with microvascular complications when compared to those without the same (mean MPV in diabetics with microvascular complications - $10.66 \pm 0.69 \mathrm{fl}$, mean MPV in diabetics without microvascular complications $10.09 \pm 0.69 \mathrm{fl}, P$ value $=0.024)$. This finding indicates that chronic hyperglycaemia and increased MPV may have a crucial role to play in the pathogenesis of microvascular complications associated with DM. The basic mechanism behind this could be the presence of larger platelets which are younger, more reactive, aggregable, contain denser granules and they also secrete more serotonin, $\beta$-thromboglobulin, and thromboxane A2 than smaller platelets. ${ }^{[20,26,27,28,29]}$ All these can produce a procoagulant effect and cause thrombotic vascular complications. This suggests a strong relationship between MPV and diabetic vascular complications.

\section{Conclusion}

MPV is a simple, convenient and cost-effective routine hematological investigation which plays a significant role in the pathogenesis of diabetes mellitus and may serve as a useful prognostic marker to herald the onset of microvascular complications in the diabetic population. High risk candidates can be identified and started on prophylactic therapy in the form of anti-platelet agents to avoid any acute events leading to lifelong debilitating consequences and even fatality. However, further studies with larger sample size need to be carried out, to emphatically establish the role of MPV in the pathogenesis of diabetes mellitus and its associated vascular complications.

\section{Abbreviations and Symbols:}

DM-diabetes mellitus, MPV-Mean platelet volume, FBGfasting blood glucose, CBC-complete blood counts.

\section{Acknowledgement}

A part of this project was funded by ICMR. 


\section{Declarations}

This article has not been published/ or is being considered for publication anywhere else.

\section{References}

1. Kodiatte TA, Manikyam UK, Rao SB, Jagadish TM, Reddy M, Lingaiah HK, Lakshmaiah V. Mean Platelet Volume in Type 2 Diabetes Mellitus. Lab Physicians. 2012; 4(1):5.

2. Abhijeet S, Kaveeshwar, Cornwal J. The current state of diabetes mellitus in India. Australasian Med J. 2014; 7(1):45-48.

3. Papanas N, Symeonidis G, Maltezos E, Mavridis G, Karavageli E, Vosnakidis T, et al. Mean platelet volume in patients with type 2 diabetes mellitus. Platelets. 2004; 15 (8):475-78

4. Hekimsoy Z, Payzin B, Ornek T, Kandogan G. Mean platelet volume in Type 2 diabetic patients. J Diabetes Complications. 2004;18 (3):173-76.

5. Shera AS, Jawad F, Maqsood A, et al. Prevalence of chronic complications and associated factors in Type 2 diabetes. $\mathrm{J}$ Pak Med Assoc. 2004; 54:54-9.

6. Khandekar MM, Khurana AS, Deshmukh SD, Kakrani $\mathrm{AL}$, Katdare AD, Inamdar AK. Platelet volume indices in patients with coronary artery disease and acute myocardial infarction: an Indian scenario. J Clin Pathol 2006; 59: 146149.

7. Citirik M, Beyazyildiz E, Simsek M, Beyazyildiz O, Haznedaroglu IC. MPV may reflect subclinical platelet activation in diabetic patients with and without diabetic retinopathy. Eye. 2015; 29: 376-379.

8. Zuberi BF, Akhtar N, Afsar S. Comparison of mean platelet volume in patients with diabetes mellitus, impaired fasting glucose and non-diabetic subjects. Singapore Med J. 2008; 49 (2):114-16.

9. Jabeen F, Fawwad A, Rizvi HA, Alvi F. Role of platelet indices, glycemic control and hs-CRP in pathogenesis of vascular complications in type-2 diabetic patients. Pak J Med Sci. 2013; 29 (1):152-156.

10. Ulutas KT, Dokuyucu R, Sefil F, Yengil E, Sumbul AT, Rizaoglu $\mathrm{H}$ et al. Evaluation of mean platelet volume in patients with type 2 diabetes mellitus and blood glucose regulation: a marker for atherosclerosis? Int J Clin Exp Med 2014; 7(4):955-961.

11. Calverley DC, Thienelt CD. Platelet structure and function in Haemostasis and thrombosis. Wintrobe's Clinical Haematology. 12th ed. Philadelphia: Lippincott Williams \&wilkins; 2009; 490-527.

12. Colwell JA, Winocour PD, Halushka PV. Do platelets have anything to do with diabetic microvascular disease? Diabetes. 1983; 32(2):14-9.

13. Sharpe PC, Trinick T. Mean platelet volume in diabetes mellitus. J Med. 1993; 86 (11):739-42.
14. Demirtunc R, Duman D, Basar M, Bilgi M, Teomete M, Garip T. The relationship between glycaemic control and platelet activity in type 2 diabetes mellitus. J Diabetes Complications. 2009; 23: 89-94.

15. Jindal S, Gupta S, Gupta R, Kakkar A, Singh HV, Gupta K, Singh S. Platelet indices in diabetes mellitus: indicators of diabetic microvascular complications. Haematology. 2011; $16(2): 86-9$.

16. Vernekar PV, Vaidya K. Comparison of Mean Platelet Volume in Type 2 Diabetics on Insulin Therapy. J Clin Diagn Res. 2013; 7 (12): 2839-40.

17. Zaccardi F, Rocca B, Pitocco D, Tanese L, Rizzi A, Ghirlanda G. Platelet mean volume, distribution width, and count in type 2 diabetes, impaired fasting glucose, and metabolic syndrome: a meta-analysis. Diabetes Metab Res Rev. 2015; 31 (4):402-10.

18. Dindar S, Cinemre H, Sengul E, Annakkaya AN. Mean platelet volume is associated with glycaemic control and retinopathy in patients with Type 2 Diabetes Mellitus. West Indian med j. 2013; 62 (6):519-23.

19. Akkerman JW, Gorter G, Sixma JJ. Regulation of glycolytic flux in human platelets: relation between energy production by glyco (geno) lysis and energy consumption. Biochim Biophys Acta. 1978; 541(2):241-50.

20. Davi G, Santilli F, Vazzanna N. Diabetes mellitus. Platelets. 3rd ed. London: Elsevier; 2013; 711-31.

21. Vinik AI, Erbas T, Park TS, Nolan R, Pittenger GL. Platelet dysfunction in type 2 diabetes. Diabetes Care. 2001; 24: 1476-85.

22. Schneider DJ. Factors contributing to increased platelet reactivity in people with diabetes. Diabetes Care. 2009; 32: $525-27$.

23. Kakouros N, Rade JJ, Kourliouros A, Resar JR. Platelet function in patients with diabetes mellitus: from atheoretical to a practical perspective. Int J Endocrinol. 2011; 2011: 742719.

24. Radha RKN, Selvam D. MPV in Uncontrolled \& Controlled Diabetics- Its Role as an Indicator of Vascular Complication. J Clin Diagn Res. 2016; 10 (8):22-26.

25. Ates O, Kiki I, Bilen H, Keles M, Koçer I, Kulaçoglu DN, et al. Association of Mean Platelet Volume With The Degree of Retinopathy in Patients with Diabetes Mellitus. Eur J Gen Med. 2009; 6: 99-102.

26. Cadirci K, Olcaysu O, Yigit D, Carlioglu A, Senay AD. Mean platelet volume in type 2 diabetic patient: is there a relationship between mean platelet volume and diabetic microvascular complications? Endocrine abstracts 2014;35:448

27. Colwell JA, Nesto RW. The platelet in diabetes-focus on prevention of ischemic events. Diabetes Care. 2003; 26: 2181-88. 
28. Chang HA, Hwang HS, Park HK, Chun MY, Sung JY. The Role of Mean Platelet Volume as a Predicting Factor of Asymptomatic Coronary Artery Disease. Korean J Fam Med. 2010; 31: 600-06.
29. Cadirci K, Olcaysu O, Yigit D, Carlioglu A, Durmaz SA. Mean platelet volume in type 2 diabetic patient: is there a relationship between mean platelet volume and diabetic microvascular complications? Endocrine Abstracts. 2014; 35: 448.

*Corresponding author:

Dr Sruthi Prasad, Associate professor, Department of Pathology, Kempegowda institute of medical sciences, Banshankari 2nd stage, Bangalore 560070,

Karnataka, India

Phone: +91 9900149469

Email: sruthi.chandra@gmail.com

Financial or other Competing Interests: None. 